\title{
Urban Forestry Management Information System Based on GIS - A Case of Tangshan City Xiaohong Wang ${ }^{1, a^{*}}$, Yajing Liu ${ }^{1, b}$,Lina Guo ${ }^{1, c}$
}

North China University of Science and Technology, Hebei Tangshan 063009, China; Hebei Key Laboratory of Mining Development and Security Technology, Hebei Tangshan 063009, China

a glwxiaohong@163.com, blyj2206@163.com, c guolina1101@163.com

Keywords: Urban forest; GIS; information management, Ecological Benefits

Abstract. GIS technology was introduced in the information management system of urban forest, and Tangshan City urban forestry management information system is established. The system has the capabilities for data acquisition, storage, analysis and updating of different kinds of spatial information. There were five modules included in the system: basic operation module, resource information management module, urban forest landscape planning and decision making module, ecological benefit analysis module, thematic map making module. This system from the perspective of urban forest management information construction, and realize the information management of the intelligent, scientific and scientific decision-making and ecological benefits of the rationalization of the analysis.

\section{Introduction}

As a kind of ecological system, urban forest is the main body, and it includes many kinds of elements, such as urban water, orchard, grassland, nursery, and so on, which is closely related to urban landscape construction, park management and urban planning. Urban forest is an important part of the dynamic balance between the energy flow and material circulation in the artificial ecosystem.

Urban forest management system based on GIS provided a digital city forest management platform. It solved the problem fundamentally that the traditional method cannot solve, and complete realization the digitization of the urban forest planning, information management and query, implement the urban forest special planning, landscape planning of and computer aided decision.

\section{System Design Object}

The overall objective of the system to position the urban forest location, information inquiry, statistics, with the aid of decision support, provide the basis for urban forest planning and landscape construction. The system can generate all kinds of thematic maps according to different needs. The system can provide services for Tangshan City forestry users to monitoring, analysis, forecasting and decision making.

\section{The General Design}

System Scenario. The system requires large amounts of data storage and computing, client software and hardware configuration recommended as shown in table 1. 
Table 1 Client hardware and software configuration

\begin{tabular}{cc}
\hline Item & Configuration Parameter \\
\hline OS & Windows XP/ Windows 7 \\
CPU & Intel Pentium 4 >2.2 GHz \\
RAM & $>1.0 \mathrm{G}$ \\
Hard drive & $>80.0 \mathrm{G}$ \\
capacity & \\
DataBase & Access2003 \\
Software & Microsoft Visual Studio 2008 \\
Requirements & .NET Framework 3.5 SP1, \\
& ArcGIS Server, ArcGIS \\
& Engine \\
\hline
\end{tabular}

General System Framework Design. System Framework and functional architecture system will eventually determine the detailed structure and function, the most obvious manifestation was the user interactive interface that was supported by the data layer, data layer includes a data input, data storage and display, query and output. The general system framework as shown in Figure 1.

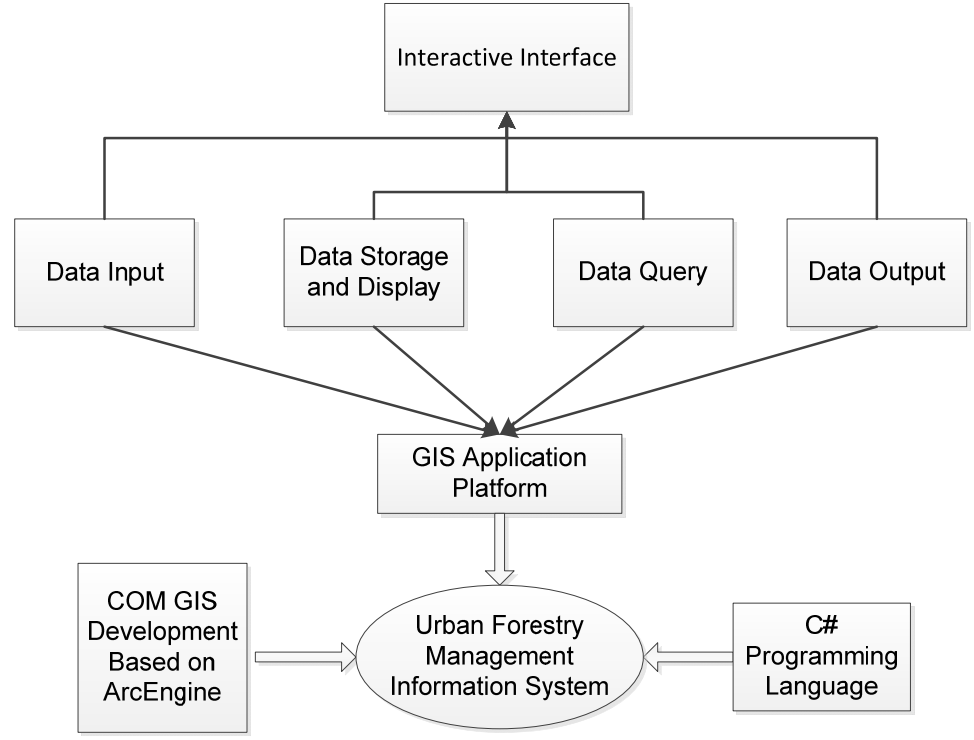

Fig.1 General System Framework Chart

Database Design. The development of urban forestry management information system needs strong support of database system. Considering the different nature of quantitative statistical or attribute data and geospatial feature information, the storage and management of the data will be stored in the attribute database and spatial database. The database framework was shown in Figure 2 .

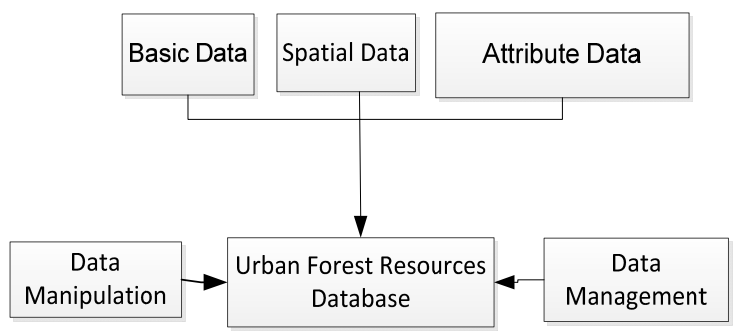

Fig.2 Database Framework 


\section{System Functional Design}

The urban forestry management information system based on GIS can complete the general information system cannot finish some special functions such as spatial data inquiry and analysis, etc. System function module is shown in Figure 3, which is related to each functional module of the system. For example, the realization of the query and spatial analysis module was depends on the map display.

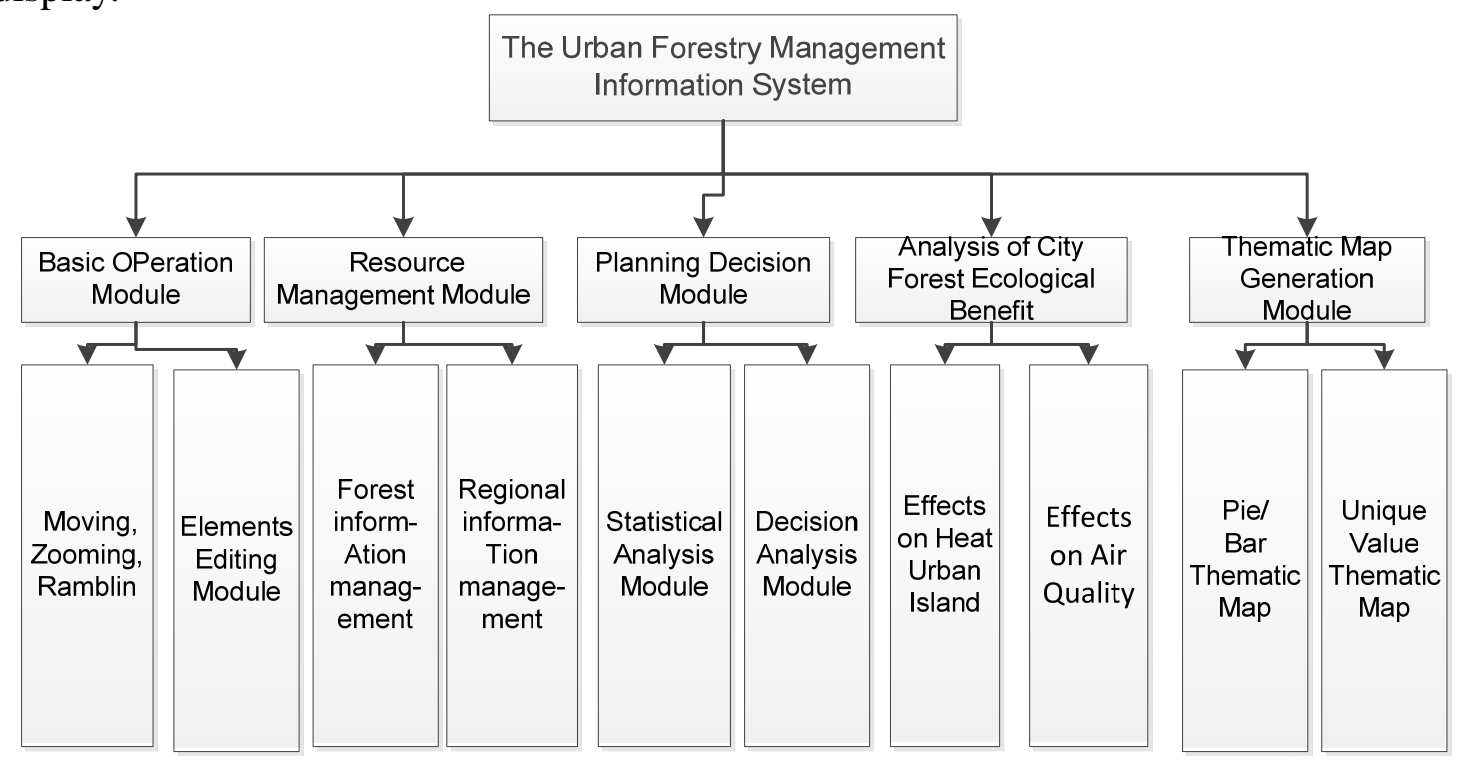

Fig.3 System Main Function Modules

Basic Operation Module. The basic operations include maps to zoom, roaming, Hawkeye and other functions, which was commonly used in functional operation.

\section{Resource Management Module.}

Resource management module provides users with forest resources information to add, delete, modify, query, but also including query attributes from the map elements or get dependency graph from the attributes, etc

Planning Decision Module.The main function of this module was to provide advice and suggestion. for the urban landscape and ecological planners by the spatial pattern of the urban forest distribution, the quantity and the relationship with the surrounding environment.

Analysis of City Forest Ecological Benefit.The module provided an analysis of the impact of urban forest on environment, included the improvement of the heat urban island effect, the influence of the ambient temperature and the improvement of air quality mainly, etc.

Thematic Map Generation Module.This functional module showed statistical results in various thematic maps way after statistical analysis.

\section{Conclusions}

Urban forestry management information systems based on GIS have provided a digital means for the management of urban forest resources. The platform provides the functions of analysis of urban environmental indicators, decision support, and the thematic map and so on which provided a scientific means and basis for urban forest management and planning and made urban ecological planning and decision-making to be reasonable and efficient. It was a modern and irreplaceable platform for the development of urban forestry in Tangshan City.

\section{Reference}

[1] XJ Wang, DC Huang, HM Li, DY Xue, RZ Zhang and XL Chen. Chinese Bulletin of Entomology,vol.43,(4)(2006), p.540-545(In Chinese).

[2] GL Zhou, C Chen, J Ye, BS Hu, FQ Liu. Acta Ecologica Sinica, vol. 27(8)( 2007), p.32-35(In 
Chinese).

[3] TY Ying, $M$ Li, WY Fan, XY Zhang. Journal of northeast forestry university, 38(8)(2010),p.100-101(In Chinese).

[4] HX Liu, GX Jin, J Wu, P Sun, C Liu, CY Xu. Journal of Beijing Forestry University, vol.10(2015),p.31-10(In Chinese).

[5] MY Li, $\mathrm{H}$ Wang, MF Zhang, $\mathrm{M} \mathrm{Hu}, \mathrm{C}$ Yu. Journal of Southwest Forestry University,vol.5(2015),p.33-35(In Chinese).

[6] RB Sun.Journal of Henan Science and Technology,vol.21(2014),p.17-19(In Chinese). 